\title{
Regulation of Alström syndrome gene expression during adipogenesis and its relationship with fat cell insulin sensitivity
}

\author{
SARA ROMANO ${ }^{1}$, GABRIELLA MILAN $^{1}$, CATERINA VERONESE$^{1}$, GAYLE B. COLLIN $^{2}$, JAN D. MARSHALL $^{2}$, \\ CINZIA CENTOBENE ${ }^{1}$, FRANCESCA FAVARETTO ${ }^{1}$, CHIARA DAL PRA ${ }^{1}$, ALESSANDRO SCARDA $^{1}$, \\ SONIA LEANDRI ${ }^{1}$, JÜRGEN K. NAGGERT ${ }^{2}$, PIETRO MAFFEI ${ }^{1}$ and ROBERTO VETTOR ${ }^{1}$ \\ ${ }^{1}$ Endocrine-Metabolic Laboratory, Internal Medicine 3, Department of Medical and Surgical Sciences, University of Padua, \\ via Ospedale 105, I-35128 Padua, Italy; ${ }^{2}$ The Jackson Laboratory, 600 Main Street, Bar Harbor, Maine 04609, USA
}

Received January 24, 2008; Accepted February 28, 2008

\begin{abstract}
Alström syndrome (ALMS) is an autosomal recessive genetic disease with characteristic phenotypical features including multi-organ fibrosis, insulin resistance, obesity and type 2 diabetes. ALMS1, a ubiquitously expressed gene mutated in ALMS patients, gives rise to a protein of unknown function localized to basal bodies of ciliated cells and centrosomes. Together with Bardet-Biedl syndrome, ALMS is a member of genetic ciliopathies, but the link between cilia/centrosome deficits and metabolic abnormalities remains to be determined. In this study for the first time we quantified Almsl expression in a cellular model of adipogenesis during the differentiation of 3T3-L1 cells. An early decrease in Alms 1 mRNA was observed during preadipocyte to adipocyte conversion. However, acute treatment of preadipocytes with the adipogenic factors did not result in significant change of Alms 1 expression. In addition, to study the possible relationship between Alms 1 and the degree of fat cell insulin sensitivity, as assessed with an insulin-dependent $2-\left[1-{ }^{3} \mathrm{H}\right]$-deoxyglucose uptake assay, we induced either a reduction or an increase in 3T3-L1 adipocytes insulin sensitivity by a chronic treatment with insulin or rosiglitazone respectively. In all these conditions Alms I expression remained unchanged. In conclusion, our results show that Alms 1 is expressed at higher level in preadipocytes suggesting a role of the gene in the early phase of adipogenesis. Moreover, changes in fat cell insulin sensitivity do not imply any effect on Alms 1 expression.
\end{abstract}

\section{Introduction}

Alström syndrome [ALMS (MIM \#203800)] is a recessively inherited disorder characterized by early retinal photoreceptor

Correspondence to: Dr Gabriella Milan, Department of Medical and Surgical Sciences, University of Padua, Via Ospedale 105, I-35128 Padua, Italy

E-mail: gabriella.milan@unipd.it

Key words: Alms1, adipogenesis, insulin sensitivity, Alström syndrome, 3T3-L1 degeneration, sensorineural hearing impairment, childhood obesity and severe insulin resistance followed by type 2 diabetes mellitus. Systemic fibrosis and multiple organ involvement including dilated cardiomyopathy, hepatic and renal failure may occur (1). ALMS is caused by mutations in $A L M S 1$, a novel gene of unknown function on chromosome 2 p13 which is ubiquitously expressed at low levels $(2,3)$.

The analysis of transcripts in humans as well as in mice indicates the presence of different splice variants in several tissue types $(2,4)$. It is possible that each protein isoform has a specific role in particular tissues and organs. Moreover, the mutations identified thus far cluster in distinct positions (mostly in exon 8,10 and 16) and may explain the phenotypic variability among ALMS patients.

ALMS1 localizes to the centrosomes and basal bodies of ciliated cells and roles in cytoplasmic microtubular organization, intracellular transport and/or cilia assembly or function have been suggested $(5,6)$. These observations led to the inclusion of ALMS in an emerging class of human genetic disorders, such as the Bardet-Biedl syndrome [BBS (MIM \#209900)], called 'ciliopathies' (7,8). BBS shares with ALMS numerous features, in particular obesity and type 2 diabetes. A recent report investigated the temporal expression pattern of genes implicated in BBS in a cellular model of adipogenesis. Although not all BBS genes are expressed in adipose tissue, some of them showed increased mRNA levels in mature adipocytes compared to preadipocytes (9).

Although the major phenotypic features of ALMS, such as severe insulin resistance, obesity and type 2 diabetes, are observed in human and in murine models $(4,10,11)$, there is little experimental evidence linking the Alms 1 gene to the development of insulin resistance, to fat cell metabolism and adipose tissue growth and differentiation.

Adipose tissue insulin sensitivity is central in the regulation of glucose and free fatty acid uptake, inhibition of lipolysis and stimulation of fatty acid synthesis in adipocytes. In addition, insulin modulates adipose tissue growth and differentiation in concert with peroxisome proliferator-activated receptor $(\operatorname{PPAR} \gamma)$, the key adipose tissue transcriptional regulator (12), by stimulation of glucose uptake together with translocation of glucose transporter 4 (GLUT4) from intracellular storage vesicles to the plasma membrane (13). 
This complex insulin-stimulated intracellular trafficking is not completely clear and is specifically regulated in distinct cells and tissues (14). The organs that are primarily involved in this process are skeletal muscle and adipose tissue and most studies about the mechanism of insulin-stimulated glucose uptake have been performed in 3T3-L1 adipocytes $(15,16)$. Moreover, evidence indicates that cytoskeleton structures are implicated in insulin-induced glucose uptake and in GLUT4 translocation in fat cells $(14,17)$. Therefore, the specific ALMS1 localization to centrosomes raises the possibility that ALMS1 could impact the GLUT4 translocation process and glucose uptake (6).

In order to study Alms 1 transcripts during adipogenesis we utilized the established murine preadipocyte cell line 3T3-L1. We aimed also to investigate in 3T3-L1 preadipocytes the acute effect of the individual substances present in the adipogenic medium on Alms 1 mRNA level. In addition, we evaluated whether modifications of insulin sensitivity could be associated with changes in Alms 1 expression in fully differentiated 3T3-L1 adipocytes.

\section{Materials and methods}

Cell culture. 3T3-L1 preadipocytes (ATCC CL-173) were grown in 24-well cell culture plates (CellStar, Greiner Bio-One International AG, Germany) in standard medium (SM), consisting of Dulbecco's Eagle's medium (DMEM, Gibco, Invitrogen Life Tecnologies, Paisley, UK), $10 \%$ bovine serum (Gibco), $150 \mathrm{U} / \mathrm{ml}$ streptomycin, $200 \mathrm{U} / \mathrm{ml}$ penicillin, $2 \mathrm{mM}$ glutamine and $1 \mathrm{mM}$ HEPES (Gibco). At confluence, adipogenic differentiation was induced by adding adipogenic medium (AM) consisting of $1 \mu \mathrm{M}$ dexamethasone, $0.5 \mathrm{mM}$ 3-isobutyl-1-methyl-xantine (IBMX, Sigma-Aldrich, St. Louis, MO, USA) and $2 \mu \mathrm{M}$ insulin (Humulin Regular A, Eli Lilly, FI, Italy). The IBMX was removed from AM after 3 days of culture. Cells were cultured at $37^{\circ} \mathrm{C}$ in a humidified atmosphere of $5 \% \mathrm{CO}_{2}$ and were collected every two days until complete differentiation (12 days). Morphological changes were monitored by microscopic analysis (Leika, Heidelberg, Germany) and by Oil-Red O staining, as described below.

Treatments of 3T3-L1 preadipocytes and adipocytes. The 3T3-L1 cell line was grown in SM for 2 days. Then, preadipocytes were stimulated with $2 \mu \mathrm{M}$ insulin, $1 \mu \mathrm{M}$ dexamethasone, $0.5 \mathrm{mM}$ IBMX, AM, $10 \mu \mathrm{M}$ rosiglitazone and AM with $10 \mu \mathrm{M}$ rosiglitazone or dimethylsulfoxide (DMSO) (Sigma-Aldrich) as solvent control for $12 \mathrm{~h}$ at $37^{\circ} \mathrm{C}$.

Adipocytes were obtained by culturing 3T3-L1 cells at confluence in AM with or without $10 \mu \mathrm{M}$ rosiglitazone. Adipocytes fully differentiated in AM were then incubated with $10 \mu \mathrm{M}$ rosiglitazone or DMSO for $24 \mathrm{~h}$ at $37^{\circ} \mathrm{C}$ (acute treatment) or chronically treated with $2 \mu \mathrm{M}$ insulin (not removed after the differentiation). The degree of fat cell differentiation was measured by Oil-Red $\mathrm{O}$ staining. The cells were washed out by culturing in SM for at least 2 days before functional (glucose uptake test) or expression analysis.

Oil-Red $O$ staining and triglyceride quantification. Cells were fixed in $10 \%$ formalin in PBS containing $\mathrm{CaCl}_{2} 0.9 \mathrm{mM}$ and $\mathrm{MgCl}_{2} 0.5 \mathrm{mM}$ (PBS-CM) for $1 \mathrm{~h}$ at $4^{\circ} \mathrm{C}$. Adipocytes were stained with Oil-Red O (Sigma-Aldrich) in 40\% isopropanol for $15 \mathrm{~min}$ at room temperature. After 3 washes in PBS-CM, Oil-Red O stain was extracted in $600 \mu \mathrm{l}$ isopropanol and the absorbance was measured at $518 \mathrm{~nm}$ by spectrophotometer (Beckman Coulter, Inc., CA, USA).

Gene expression. Total RNA was extracted using the RNEasy mini kit (Qiagen GmbH, Hilden, Germany), treated with DNase Treatment \& Removal Reagents (Ambion, Inc, Austin, TX, USA) and $2 \mu \mathrm{g}$ was reverse-transcribed with $150 \mathrm{ng}$ of random hexamers and $200 \mathrm{U}$ of M-MLV RT (Promega Corp., Madison, WI, USA), according to the protocol recommended by the manufacturer.

PCR was carried out using Hot Star Taq DNA polymerase (Qiagen) in $25 \mu \mathrm{l}$ of standard buffer with $1.5 \mathrm{mM} \mathrm{MgCl}_{2}$, $200 \mu \mathrm{M}$ of each dNTP and $0.5 \mu \mathrm{M}$ of primers for different adipogenic markers, as Fatty acid binding protein 2 (Fabp-2), Fatty acid transporter $(\mathrm{Cd} 36)$, Adiponectin (Adipo $Q$ ) and Lipoprotein lipase $(L l p)$ : primer sequences and amplification conditions are available upon request. Amplification reaction $(10 \mu 1)$ was separated by electrophoresis on agarose gels, visualized with ethidium bromide staining, using Image Master VDS (Amersham Pharmacia Biotech Europe GmbH, Freiburg, Germany) and densitometrically analysed with Image Master Total Lab 2.00 software. mRNA levels were expressed as the ratio of signal intensity for the target genes relative to that for $18 S$ rRNA in arbitrary units (a.u.).

In regard to Alms 1 transcripts, they were amplified using two primer sets, located in exon 8 (Alms1 ex8) and in exon 16 (Alms1 ex16). The oligonucleotide primers for mouse Alms 1 ex8 (NM_145223) (forward 5'-GAA AAT ATG GCA CTG AAA CG-3' and reverse 5'-TTC CCA ATT TCC AAC ACC3'), Alms1 ex16 (forward 5'-GTG GTG CCT GTG ATA CGA AAG A-3' and reverse 5'-AGG CCC GGA GTG AAT GTG-3') and for the house-keeping $\beta 2$-microglobulin gene (forward 5'-GCT TCA GTC GTC AGC ATG G-3' and reverse 5'-CAG TTC AGT ATG TTC GGC TTC C-3') were designed using the Omiga $^{\text {TM }} 2.0$ software (Oxford Molecular Ltd., WI, USA). qPCR was carried out with SYBR Green PCR Master Mix (Applied Biosystems, Forster City, CA, USA) on a DNA Engine Opticon $^{\mathrm{TM}} 2$ Continuous Fluorescence Detection System (MJ Research, MA, USA). Each cDNA sample was assayed in duplicate and a no template control was included in every reaction. Each 30- $\mu 1$ reaction contained $5 \mu 1$ first-strand cDNA (10 ng), $15 \mu 1$ 2X SYBR Green PCR Master Mix (Applied Biosystems, Milan, Italy) and $300 \mathrm{nM}$ of each forward and reverse primers. The activation step $\left(95^{\circ} \mathrm{C}\right.$ for $\left.10 \mathrm{~min}\right)$ was followed by 45 cycles of $94^{\circ} \mathrm{C} \mathrm{x} 15 \mathrm{sec}, 53^{\circ} \mathrm{C}$ x $30 \mathrm{sec}$ and $72^{\circ} \mathrm{C}$ x $30 \mathrm{sec}$ for Alms1 ex8 (amplicon of $237 \mathrm{bp}$ ), by 45 cycles of $95^{\circ} \mathrm{C} \times 15 \mathrm{sec}$ and $60^{\circ} \mathrm{C} \times 1 \mathrm{~min}$ for Alms 1 ex 16 (amplicon of $95 \mathrm{bp}$ ) and by 45 cycles of $95^{\circ} \mathrm{C} \times 15 \mathrm{sec}, 57^{\circ} \mathrm{C} \times 30 \mathrm{sec}$ and $72^{\circ} \mathrm{C}$ x $30 \mathrm{sec}$ for $\beta 2$-microglobulin (amplicon of $149 \mathrm{bp}$ ).

Standard curves were obtained using cDNA from 3T3-L1 cells by plotting values for log cDNA quantity (in a.u.) versus cycle threshold. For each sample, Alms 1 expression values were normalized by $\beta 2$-microglobulin mRNA content and reported as a.u. ratio.

Assessment of glucose uptake. Adipocytes were incubated at $37^{\circ} \mathrm{C}$ for $2 \mathrm{~h}$ in serum-free medium and then treated with 


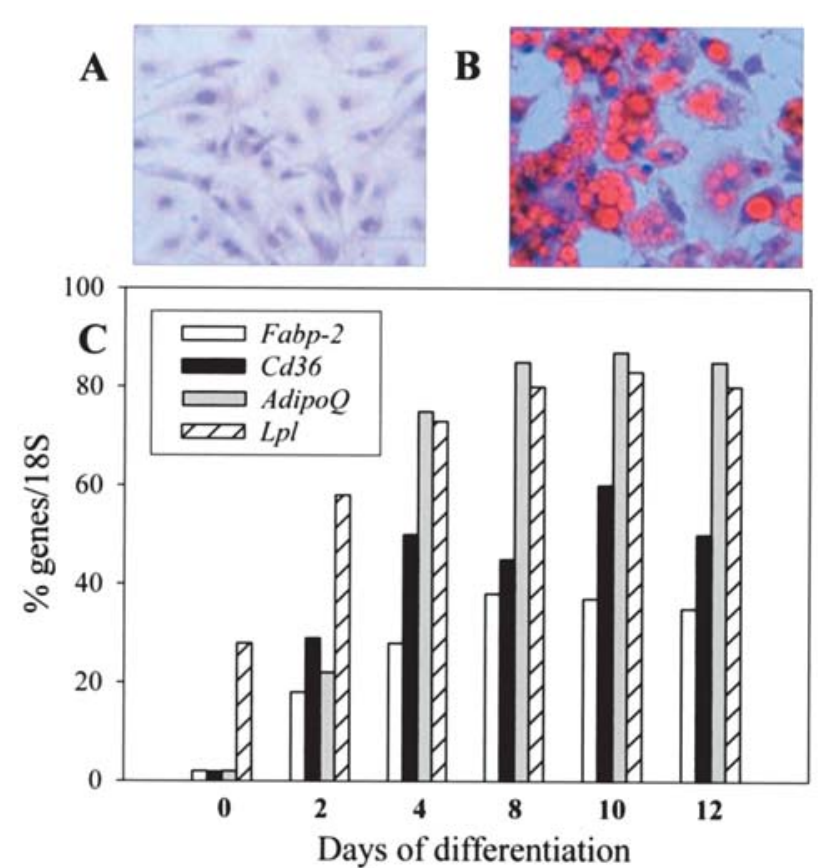

Figure 1. 3T3-L1 adipogenic differentiation. (A) 3T3-L1 preadipocytes. (B) 3T3-L1 adipocytes after adipogenic differentiation. The lipid droplets of mature fat cells are stained with Oil-Red O; Giemsa and May-Grunwald are used as counterstaining. (C) mRNA expression normalized to $18 S$ rRNA content of Fatty acid binding protein 2 (Fabp-2), Fatty acid transporter $(C d 36)$, Adiponectin $($ Adipo $Q)$ and Lipoprotein lipase $(L p l)$ during adipogenic differentiation in a representative experiment.

different concentrations of insulin $(0,100 \mathrm{nM}$ or $2 \mu \mathrm{M})$ for $1 \mathrm{~h}$ at $37^{\circ} \mathrm{C}$. The assay was initiated by the addition of $300 \mu \mathrm{l}$ of a solution of $50 \mu \mathrm{M}$ D-glucose and $1.5 \mu \mathrm{Ci} / \mathrm{ml} 2$-Deoxyglucose (Amersham-Biosciences, Piscataway, NJ, USA). After $15 \mathrm{~min}$ at $37^{\circ} \mathrm{C}$, the assay was terminated by two rapid washes in ice-cold PBS. Cells were solubilized in $500 \mu 1 \mathrm{PBS}$ with $0.1 \%$ Triton $\mathrm{X}-100$ and the radioactivity was measured using a $ß$-counter (Wallace-Perkin-Elmer, MA, USA). Total protein was quantified using a Coomassie (Bradford) Protein Assay Kit (Pierce, Rockford, IL, USA). The insulin-induced glucose uptake was normalized to total protein content and reported as percentage of the basal value.

Statistical analyses. Statistical analysis was performed using unpaired Student's t-test (two-tailed) and analysis of variance. Differences were considered significant at $\mathrm{P}<0.05$.

\section{Results}

Adipogenic differentiation of 3T3-L1 cells. To assess the differentiation of 3T3-L1 we monitored morphological changes during the adipogenic process by microscopy. After 12 days in AM, we obtained fully differentiated adipocytes, as shown by Oil-Red O staining of lipid droplets in red (Fig. 1B).

Expression levels of well-known adipose-cell specific genes (Fabp-2, Cd36, Adipo $Q$ and $L p l$ ) were measured during the time course of adipogenic differentiation (Fig. 1C). These genes were absent or weakly expressed in 3T3-L1 preadipocytes and were highly up-regulated as a result of adipogenesis. Particularly, Fabp-2, Cd36 and AdipoQ levels

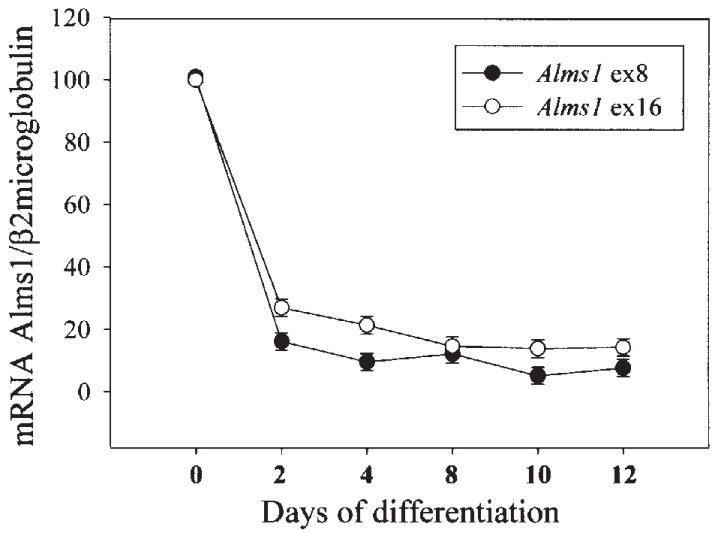

Figure 2. Alms 1 mRNA expression during 3T3-L1 adipogenic differentiation. Alms 1 expression was quantified with 2 different primer sets localized in exon 8 (black circles) and exon 16 (white circles) of mRNA sequence, respectively. Expression values are means \pm SD of three different experiments, normalized to $\beta 2$-microglobulin mRNA content. The basal level of Alms1 expression in preadipocytes ( 0 days of differentiation) is indicated at $100 \%$.

increased the second day of the differentiation process, peaking at the fourth day after the addition of AM and then maintaining steady levels thereafter. Conversely, $L p l$ was expressed at low levels in preadipocytes and its expression increased steadily during the conversion to mature fat cells.

Alms1 expression during 3T3-L1 adipogenic differentiation. Modifications in Alms1 expression were quantified by RTqPCR with 2 different primer sets, localized in exons 8 and 16, to measure the putative presence of different transcripts. A significant decrease in mRNA levels of Alms 1 was observed throughout adipogenesis with both primers, beginning from the second day after the addition of AM. The expression levels in fully differentiated adipocytes were $20 \%$ of those observed in preadipocytes (Fig. 2).

Effect of different adipogenic substances on Alms 1 expression in preadipocytes. We analyzed Alms 1 transcripts by RT-qPCR, to investigate the possible role of the single AM components and of rosiglitazone in the reduction of Alms 1 mRNA expression found in mature fat cells. No significant changes in Alms 1 expression in 3T3-L1 preadipocytes were observed considering all the different treatments performed with both the primer sets used (Fig. 3).

Insulin sensitivity and Alms 1 expression in 3T3-L1 mature adipocytes. To compare Alms 1 expression and insulin resistance in mature adipocytes, insulin-induced glucose uptake assays were performed on 3T3-L1 cells and Alms 1 mRNA levels were quantified. Mature adipocytes differentiated in the presence of rosiglitazone displayed greater insulin sensitivity with respect to control cells differentiated without the drug $(600 \%$ vs $400 \%$ increase of basal glucose uptake upon stimulation with $2 \mu \mathrm{M}$ of insulin). The number, size and morphology of adipocytes, estimated by microscopic examination and measured by Oil-Red $\mathrm{O}$ staining, were very similar, regardless of the presence of rosiglitazone during the differentiation and irrespective of the different treatments 


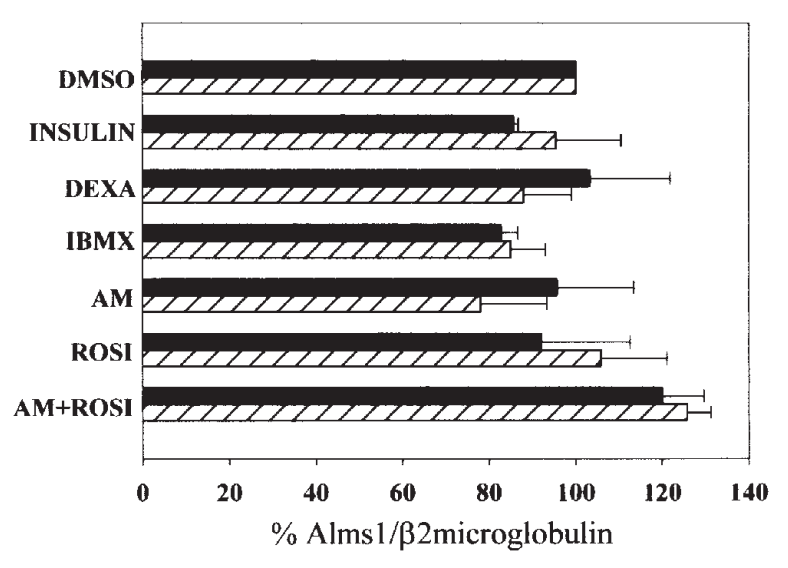

Figure 3. Alms 1 mRNA expression in 3T3-L1 preadipocytes treated with different adipogenic cocktails. Alms 1 mRNA was quantified with 2 different primer sets localized in exon 8 (black bars) and exon 16 (hatched bars) of mRNA sequence. Expression values are means \pm SD of three different experiments normalized to $\beta 2$-microglobulin mRNA content. 3T3-L1 preadipocytes were incubated with the adipogenic additives indicated for $12 \mathrm{~h}$ (acute treatment). Alms 1 expression in control cells (DMSO) is indicated at $100 \%$ for each primer sets. DMSO, dimethylsulfoxide; Insulin, $2 \mu \mathrm{M}$ insulin; DEXA, $1 \mu \mathrm{M}$ dexamethasone; IBMX, $0.5 \mathrm{mM}$ 3-isobutyl-1-methilxantine; AM, adipogenic medium $(2 \mu \mathrm{M}$ insulin $+1 \mu \mathrm{M}$ DEXA $+0.5 \mathrm{mM}$ IBMX); ROSI, $10 \mu \mathrm{M}$ rosiglitazone; $\mathrm{AM}+\mathrm{ROSI}$, adipogenic medium + $10 \mu \mathrm{M}$ rosiglitazone.

performed (Fig. 4A, inner panel). However, despite the protocol of differentiation used, mature adipocytes did not increase their insulin responsiveness with rosiglitazone treatment for $24 \mathrm{~h}$ (Fig. 4A and data not shown).

While 3T3-L1 adipocytes were generated by a 12 days culture in AM containing $2 \mu \mathrm{M}$ insulin, it is important to consider that when insulin was not removed after the differentiation, the adipocytes were insulin resistant (Fig. 4A).

Nevertheless, despite the distinct conditions of insulin sensitivity generated, no significant difference in Alms 1 mRNA expression was observed in adipocytes differently treated, independently of the primer sets used (Fig. 4B).

\section{Discussion}

In this study, we investigated Alms1 regulation in the 3T3-L1 cell line during the adipogenic process and its possible relationship with fat cell insulin sensitivity. Alms 1 mRNA is predominantly expressed in preadipocytes, whereas it is clearly down-regulated in mature adipocytes, suggesting distinct functions for Alms 1 in adipose tissue. On the contrary, the majority of $B B S$ genes expressed in mouse adipose tissue, are reported to be up-regulated together with fat cell maturation (9). Despite these contrasting results, the genes involved in both syndromes showed the greatest variations during early adipogenesis. The progressive decrease of Alms 1 expression during the early phase of adipogenic differentiation led us to speculate on a role of $A L M S 1$, when the preadipocyte changes its phenotypic characteristic from a fibroblast-like cell to a fat cell. In fact, gene expression profiling of 3T3-L1 cells during adipogenesis showed that different genes of the cytoskeleton were down-regulated as the first step of cellular differentiation, before any morphological changes (18). The
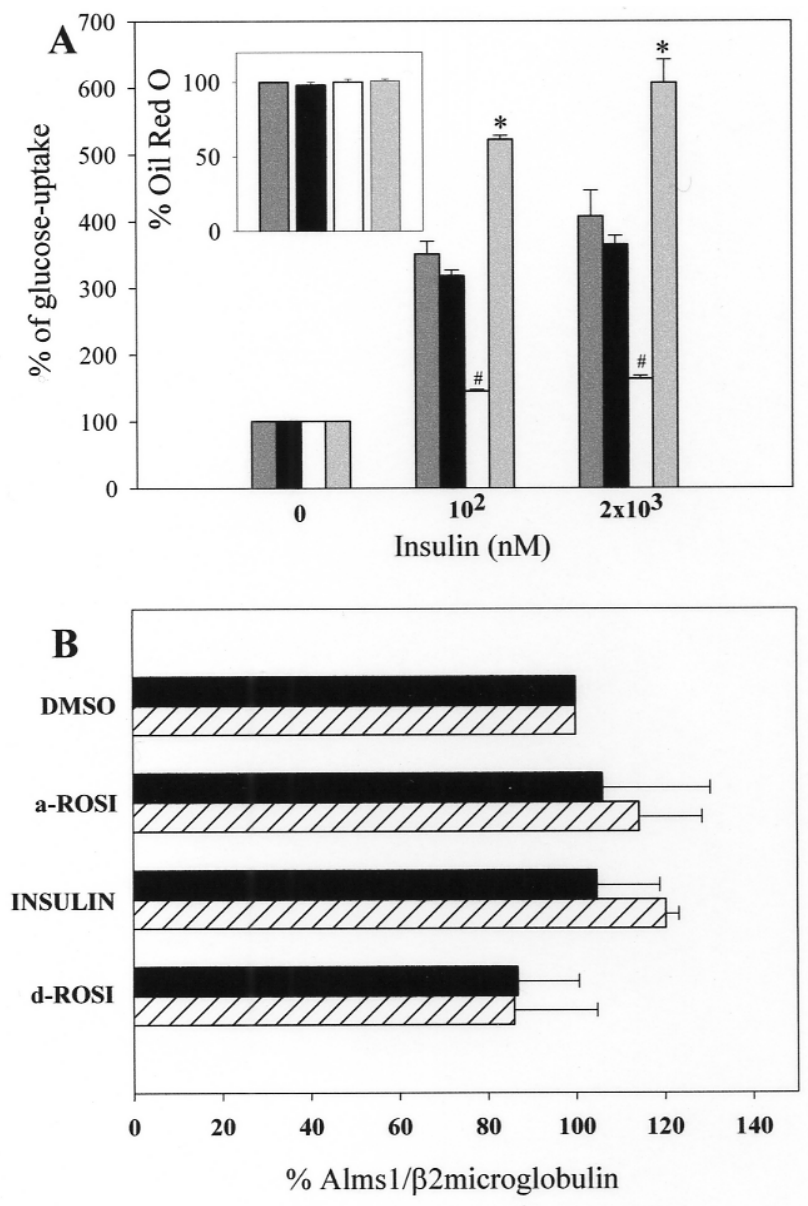

Figure 4. Insulin-dependent glucose uptake and Alms 1 mRNA expression in 3T3-L1 adipocytes. (A) 3T3-L1 cells were differentiated into mature adipocytes in standard adipogenic medium (AM) and then treated for $24 \mathrm{~h}$ with DMSO as a control (dark-gray bars) or with $10 \mu \mathrm{M}$ rosiglitazone (black bars) or maintained in $2 \mu \mathrm{M}$ insulin after differentiation (white bars). The lightgrey bars represent 3T3-L1 cells differentiated in AM added with $10 \mu \mathrm{M}$ rosiglitazone during all adipogenesis. Differentiated mature adipocytes were stimulated with insulin at the concentration indicated. The basal level of glucose uptake of the unstimulated cells is indicated at $100 \%$ for each condition. ${ }^{*} \mathrm{P}<0.05 \mathrm{AM}+$ rosiglitazone vs. AM; ${ }^{\text {}} \mathrm{P}<0.05$ insulin vs. DMSO. Quantification of Oil-Red O staining by spectrophotometer is reported in the inner panel. The OD of 3T3-L1 control adipocytes (DMSO) is indicated at $100 \%$. (B) Alms 1 mRNA was quantified with 2 different primer sets localized in exon 8 (black bars) and exon 16 (hatched bars) of mRNA sequence. Expression values are means \pm SD of three different experiments normalized to $\beta 2$-microglobulin mRNA content. 3T3-L1 adipocytes have been generated and treated as reported in (A). Alms 1 expression in control cells (DMSO) is indicated at $100 \%$ for each primer sets. DMSO, dimethylsulfoxide; a-ROSI, acute treatment with $10 \mu \mathrm{M}$ rosiglitazone; Insulin, chronic treatment with $2 \mu \mathrm{M}$ insulin; d-ROSI, differentiation in adipogenic medium added with $10 \mu \mathrm{M}$ rosiglitazone.

putative functional relationship of ALMS1 with basal bodies of ciliated cells suggests that ALMS1 may be important for the assembly of these structures. Therefore the role of ALMS1 in the fibroblast-like 3T3-L1 could be much more important than in the 3T3-L1 adipocytes and ALMS1 disruption could justify the presence of functional alterations of fibroblast cells including their proliferative, collagen biosynthetic and differentiative properties. It is noteworthy that Alström patients display not only a propensity to accumulate fat at the visceral level, but a strong susceptibility to develop a multi-organ fibrosis (1). Nevertheless, the 
functional significance of early Alms 1 expression and its impact on adipogenic differentiation remains to be explored. Alms 1 may play a role in modulating the adipogenic process and the decline of Alms 1 could allow the differentiation and proliferation of adipose cells. The disruption of the gene may thus contribute to the development of obesity in ALMS patients, possibility supported by the observations carried out also in the different animal models of ALMS $(4,10,11)$. However, it seems unlikely that Alms 1 could directly influence adipose tissue differentiation acting on the well recognized classic pathway. In fact, we have been unable to induce modulation in Alms 1 expression in preadipocytes by treatment with the adipogenic factors present in the AM (including insulin) and rosiglitazone, which activates PPAR $\gamma$, an essential transcription factor for normal adipogenesis (19). These drugs are known to trigger the adipogenic differentiation pathway and to modulate insulin sensitivity. Nonetheless, these acute treatments did not change Alms 1 expression in preadipocytes, as it has been described for other adiposespecific genes involved in obesity and insulin resistance (20,21).

ALMS shares some clinical features with BBS (abdominal obesity, insulin resistance and type 2 diabetes) as well as molecular defects at the basal bodies of ciliated cells $(5,7,22)$. These findings suggest that ciliary or vesicular transport deficits may contribute to the pathogenesis of the metabolic abnormalities present in these diseases (6). In particular, an impaired translocation of intracellular membrane vesicles containing GLUT4 to the plasma membrane could explain the appearance of a severe insulin resistance (23).

In order to study the relationships between Almsl expression and insulin sensitivity in mature fat cells, 3T3-L1 adipocytes were treated with rosiglitazone or with high concentrations of insulin. It is indeed well known that PPAR $\gamma$ activity is essential in regulating adipose tissue insulin sensitivity and glucose homeostasis $(19,24-26)$ leading also to increased expression of GLUT4 in adipose tissue (27). Recent studies demonstrated that PPAR $\gamma$ knockdown attenuates insulinstimulated glucose uptake in 3T3-L1 adipocytes, providing direct evidence that PPAR $\gamma$ is an important modulator of insulin-stimulated glucose uptake in these cells, involving both GLUT4 translocation and the initial insulin-induced phosphorylation steps (28). It is important to note that in our experiments only 3T3-L1 adipocytes differentiated in the presence of rosiglitazone highlighted an increase in insulininduced glucose uptake over control, whereas a short-term treatment with the drug did not modify fat cell insulin sensitivity. However, the improvement of fat cell insulin sensitivity did not influence Alms 1 expression. Thus, it is possible to argue that the increased rate of adipogenesis and the worsening effect on insulin sensitivity produced by the functional disruption of Alms 1 in both ALMS patients and in animal models does not involve the PPAR $\gamma$ transcription factor.

The data we obtained confirm the results from several studies that chronic exposure to insulin strikingly attenuates the acute insulin effect on fat cell glucose uptake. This phenomenon has been attributed to reduced expression levels and/or activity states of factors involved in insulin post-receptor signaling and of GLUT4 in 3T3-L1 adipocytes, producing a defect in the ability of the cell to respond to acute insulin stimulation with an increase in GLUT4 translocation and glucose transport $(29,30)$.

Since Alms 1 is likely involved in cytoskeleton function, we investigated if 3T3-L1 adipocytes chronically exposed to insulin and then became insulin-resistant could change their Alms 1 expression. This was not observed in our experiments.

The fact that most of ALMS1 mutations are in specific regions of the gene together with the identification of several tissue-specific splice variants may explain the inter-individual variability and the complexity of ALMS phenotypes. For this reason, we quantified Alms 1 expression using two primers designed in different positions of the mRNA sequence in order to track the regulation of transcripts different in size. The two Alms 1 variants putatively present in 3T3-L1 cells only slightly differ in their relative amount and essentially showed the same pattern of expression during the adipogenic differentiation. Thus, they are not differentially regulated during adipogenesis and/or by agents well known to affect fat cell insulin sensitivity.

In conclusion, our results show that fat cell insulin resistance, as obtained by chronic insulin exposure, or the improvement of fat cell insulin action on glucose transport, by chronic rosiglitazone treatment, do not display any direct regulatory effect on Almsl expression. Moreover, our data suggest a role of Alms 1 in the early phase of the adipogenic process from fibroblast like cell to mature adipocyte in 3T3-L1 cellular model.

\section{Acknowledgements}

This work was supported by grant 2005060925_002 PRIN (Programmi di Ricerca Scientifica di Rilevante Interesse Nazionale) from the MiUR (Ministero dell'Istruzione, dell'Università e della Ricerca) given to R. Vettor. G.B. Collin, J.D. Marshall and J.K. Naggert were supported by National Institues of Health grant R01 HD036878.

\section{References}

1. Marshall JD, Bronson RT, Collin GB, Nordstrom AD, Maffei P, Paisey RB, Carey C, Macdermott S, Russell-Eggitt I, Shea SE, Davis J, Beck S, Shatirishvili G, Mihai CM, Hoeltzenbein M, Pozzan GB, Hopkinson I, Sicolo N, Naggert JK and Nishina PM: New Alström syndrome phenotypes based on the evaluation of 182 cases. Arch Intern Med 165: 675-683, 2005.

2. Collin GB, Marshall JD, Ikeda A, So WV, Russell-Eggitt I, Maffei P, Beck S, Boerkoel CF, Sicolo N, Martin M, Nishina PM and Naggert JK: Mutations in ALMS1 cause obesity, type 2 diabetes and neurosensory degeneration in Alström syndrome. Nat Genet 31: 74-78, 2002

3. Hearn T, Renforth GL, Spalluto C, Hanley NA, Piper K, Brickwood S, White C, Connolly V, Taylor JF, Russell-Eggitt I, Bonneau D, Walker M and Wilson DI: Mutation of ALMS1, a large gene with a tandem repeat encoding 47 amino acids, causes Alström syndrome. Nat Genet 31: 79-83, 2002.

4. Collin GB, Cyr E, Bronson R, Marshall JD, Gifford EJ, Hicks W, Murray SA, Zheng QY, Smith RS, Nishina PM and Naggert JK: Alms1-disrupted mice recapitulate human Alström syndrome. Hum Mol Genet 14: 2323-2333, 2005.

5. Andersen JS, Wilkinson CJ, Mayor T, Mortensen P, Nigg EA and Mann M: Proteomic characterization of the human centrosome by protein correlation profiling. Nature 426: 570-574, 2003.

6. Hearn T, Spalluto C, Phillips VJ, Renforth GL, Copin N, Hanley NA and Wilson DI: Subcellular localization of ALMS1 supports involvement of centrosome and basal body dysfunction in the pathogenesis of obesity, insulin resistance, and type 2 diabetes. Diabetes 54: 1581-1587, 2005. 
7. Badano JL, Mitsuma N, Beales PL and Katsanis N: The ciliopathies: an emerging class of human genetic disorders. Annu Rev Genomics Hum Genet 22: 125-148, 2006.

8. Blacque OE and Leroux MR: Bardet-Biedl syndrome: an emerging pathomechanism of intracellular transport. Cell Mol Life Sci 63: 2145-2161, 2006.

9. Forti E, Aksanov O and Birk RZ: Temporal expression pattern of Bardet-Biedl syndrome genes in adipogenesis. Int J Biochem Cell Biol 39: 1055-1062, 2007.

10. Arsov T, Silva DG, O'Bryan MK, Sainsbury A, Lee NJ, Kennedy C, Manji SS, Nelms K, Liu C, Vinuesa CG, De Kretser DM, Goodnow CC and Petrovsky N: Fat aussie - a new Alström syndrome mouse showing a critical role for ALMS1 in obesity, diabetes, and spermatogenesis. Mol Endocrinol 20: 1610-1622, 2006.

11. Li G, Vega R, Nelms K, Gekakis N, Goodnow C, McNamara P, Wu H, Hong NA and Glynne R: A role for Alström syndrome protein, Alms1, in kidney ciliogenesis and cellular quiescence. PLoS Genet 3: e8, 2007

12. Vidal-Puig AJ, Considine RV, Jimenez-Linan M, Werman A, Pories WJ, Caro JF and Flier JS: Peroxisome proliferatoractivated receptor gene expression in human tissues. Effects of obesity, weight loss, and regulation by insulin and glucocorticoids. J Clin Invest 99: 2416-2422, 1997.

13. Hara K, Yonezawa K, Sakaue H, Ando A, Kotani K, Kitamura T, Kitamura Y, Ueda H, Stephens L, Jackson TR, et al: 1-Phosphatidylinositol 3-kinase activity is required for insulin-stimulated glucose transport but not for RAS activation in $\mathrm{CHO}$ cells. Proc Natl Acad Sci USA 91: 7415-7419, 1994.

14. Watson RT, Kanzaki M and Pessin JE: Regulated membrane trafficking of the insulin-responsive glucose transporter 4 in adipocytes. Endocr Rev 25: 177-204, 2004.

15. Mulder AH, Tack CJ, Olthaar AJ, Smits P, Sweep FC and Bosch RR: Adrenergic receptor stimulation attenuates insulinstimulated glucose uptake in 3T3-L1 adipocytes by inhibiting GLUT4 translocation. Am J Physiol Endocrinol Metab 289: E627-E633, 2005.

16. Yu C, Cresswell J, Loffler MG and Bogan JS: The glucose transporter 4-regulating protein TUG is essential for highly insulinresponsive glucose uptake in 3T3-L1 adipocytes. J Biol Chem 282: 7710-7722, 2007

17. Liu LB, Omata W, Kojima I and Shibata H: Insulin recruits GLUT4 from distinct compartments via distinct traffic pathways with differential microtubule dependence in rat adipocytes. J Biol Chem 278: 30157-30169, 2003.

18. Pacenti M, Barzon L, Favaretto F, Fincati K, Romano S, Milan G, Vettor R and Palu G: Microarray analysis during adipogenesis identifies new genes altered by antiretroviral drugs. AIDS 20: 1691-1705, 2006
19. Tontonoz P, Hu E and Spiegelman BM: Stimulation of adipogenesis in fibroblasts by PPAR gamma 2, a lipid-activated transcription factor. Cell 79: 1147-1156, 1994.

20. Fasshauer M, Klein J, Neumann S, Eszlinger M and Paschke R: Hormonal regulation of adiponectin gene expression in 3T3-L1 adipocytes. Biochem Biophys Res Commun 290: 1084-1089, 2002.

21. Haugen F, Jorgensen A, Drevon CA and Trayhurn P: Inhibition by insulin of resistin gene expression in 3T3-L1 adipocytes. FEBS Lett 507: 105-108, 2001.

22. Bornens M: Centrosome composition and microtubule anchoring mechanisms. Curr Opin Cell Biol 14: 25-34, 2002.

23. Garvey WT, Maianu L, Zhu JH, Brechtel-Hook G, Wallace P and Baron AD: Evidence for defects in the trafficking and translocation of GLUT4 glucose transporters in skeletal muscle as a cause of human insulin resistance. J Clin Invest 101: 2377-2386, 1998

24. Debril MB, Renaud JP, Fajas L and Auwerx J: The pleiotropic functions of peroxisome proliferator-activated receptor gamma. J Mol Med 79: 30-47, 2001.

25. Mukherjee R, Hoener PA, Jow L, Bilakovics J, Klausing K, Mais DE, Faulkner A, Croston GE and Paterniti JR Jr: A selective peroxisome proliferator-activated receptor-gamma (PPAR-gamma) modulator blocks adipocyte differentiation but stimulates glucose uptake in 3T3-L1 adipocytes. Mol Endocrinol 14: 1425-1433, 2000.

26. Picard F and Auwerx J: PPAR(gamma) and glucose homeostasis. Annu Rev Nutr 22: 167-197, 2002.

27. Tamori Y, Masugi J, Nishino N and Kasuga M: Role of peroxisome proliferator-activated receptor-gamma in maintenance of the characteristics of mature 3T3-L1 adipocytes. Diabetes 51: 2045-2055, 2002

28. Liao W, Nguyen MT, Yoshizaki T, Favelyukis S, Patsouris D, Imamura T, Verma IM and Olefsky JM: Suppression of PPARgamma attenuates insulin-stimulated glucose uptake by affecting both GLUT1 and GLUT4 in 3T3-L1 adipocytes. Am J Physiol Endocrinol Metab 293: E219-E227, 2007.

29. Pryor PR, Liu SC, Clark AE, Yang J, Holman GD and Tosh D: Chronic insulin effects on insulin signalling and GLUT4 endocytosis are reversed by metformin. Biochem J 348: 83-91, 2000.

30. Ricort JM, Tanti JF, Van Obberghen E and Le MarchandBrustel Y: Alterations in insulin signalling pathway induced by prolonged insulin treatment of 3T3-L1 adipocytes. Diabetologia 38: 1148-1156, 1995. 